\title{
Evaluation of the Corrosion Rate of Aluminum 6063 in Petrol, Kerosene and Water
}

\author{
Adekunle N.O. ${ }^{1 *}$, Aiyedun P.O. ${ }^{1}$, Kuye S.I. ${ }^{1}$ and Adetunji, R.O. ${ }^{1}$ \\ ${ }^{1}$ Department of Mechanical Engineering, Federal University of Agriculture, Abeokuta, Nigeria \\ Corresponding Author: *noadekunle@yahoo.com
}

\begin{abstract}
The unparalleled combinations of properties of aluminum and its alloy makes aluminum one of the most versatile, economical, and attractive metallic materials for a broad range of uses. This study was carried out to evaluate the influence of kerosene, petrol and water on the corrosion performance of three samples of aluminum 6063 alloy (A and B sourced locally while sample $C$ is an imported material). The corrosion rate was determined both by weight loss and Potentiostatics method, and the microstructure of the samples after five weeks of immersion also was examined with the aid of an optical microscope. Samples A, B and $C$ were immersed in the media for five (5) weeks duration. The cumulative corrosion rate was measured at the end of each week. The average corrosion rates using the weight loss method for $A$ in petrol, kerosene and distilled water were 3.100E-4, 4.905 E-4 and 6.205 E-4; for B were 4.367 E-4, 2.703 E-4 and 2.147 E-4; and those of C were 4.550 E-4, 2.257 E-4 and 1.633 E-4 respectively. Similarly, the average corrosion rate using Potentiostatics method of $A$ in petrol, kerosene and distilled water were 0.586E-3, 0.643E-3 and $0.454 E-3$; for $B$ were 0.206E-3, 0.197E-3 and 0.298E-3; and those of $C$ were 0.183E-3, 0.232E-3 and 0.407E-3 respectively. The average result showed that Sample A had the highest corrosion rate. The media which corroded the samples the most was petrol.
\end{abstract}

Keywords: Corrosion, Aluminum, Petrol, Kerosene, Water

\subsection{Introduction}

Aluminum alloys are second only to steels in use as structural metals (Davis, 2001). The three main properties on which the application of aluminum is based are its low density of approximately 2.7 $\mathrm{g} / \mathrm{cm}^{3}$, high mechanical strength achieved by suitable alloying and heat treatments, and its relatively high corrosion resistance especially in its pure state. Other valuable properties include high thermal and electrical conductance, reflectivity, high ductility and resultant low working cost, magnetic neutrality, high scrap-value, and non-poisonous and colourless nature of its corrosion products which facilitates its use in the chemical and food-processing industries (Sheasby and Pinner, 2001). It has been stated that corrosion can be fast or slow depending on the material and environmental factors (Syed, 2006).

The corrosion resistance of aluminum alloy is the result of their ability to form a natural oxide film on the surface in different media (Al-Karafi, 1996; El-Shafei et al., 2004; Belkhaouda et al., 2010). Aluminum has a natural corrosion protection from its oxide layer, but may corrode if exposed to aggressive environments (Kciuk et al., 2010). The behaviour of aluminum and its alloys in aqueous environments depends on several parameters such as the surface properties of the material, nature, temperature, $\mathrm{pH}$ and the composition of the aggressive solution (Belkhaouda et al., 2010). Aluminum alloys have excellent corrosion resistance to a wide variety of exposure conditions. Usually they corrode by pitting rather than by uniform corrosion (Melchers, 2015).

Copper additions, which augment strength in many of these alloys, are limited to small amounts to minimize effects on corrosion resistance. At copper levels higher than $0.5 \%$ some intergranular corrosion can occur in some tempers (e.g. T4 and T6). However, this intergranular corrosion does not result in susceptibility to exfoliation. When the magnesium and silicon contents in a 6xxx alloy are 
balanced (in proportion to form only $\mathrm{Mg}_{2} \mathrm{Si}$ ), corrosion by intergranular penetration is slight in most commercial environments. If the alloy contains silicon beyond that needed to form $\mathrm{Mg}_{2} \mathrm{Si}$ or contains a high level of cathodic impurities, susceptibility to intergranular corrosion increases (Davis, 2001).

Nuhu (2012) investigated the response of aluminum specimens immersed in saline water and one molar aqueous solution of acetic and sulphuric acids towards corrosion inhibitive actions of oil locally extracted from seeds of watermelon. Reasonable corrosion and inhibition occurred in specimens immersed in solutions of sulphuric and acetic acid while weight losses in specimens immersed in saline water were very minimal and beyond detectable limits of weighing apparatus used.

Seri and Kudo (2009) investigated the corrosion behaviour of aluminum alloy in ethanol. It was seen that aluminum alkoxide (aluminum tri-ethoxide) as corrosion product will produce hydrogen peroxide on the way of chain process of productions of ethyl chloride, diethyether and ethyether peroxide. It is also pointed out that the hydrogen peroxide will play a strong cathodic role in further pitting corrosion process. The aim of this paper is to study corrosion rate of structural aluminum alloys 6063 in different media.

\subsection{Materials and Methods}

\subsection{Materials}

Three samples of aluminum 6063 alloy were used for the study. Samples A and B were sourced locally while Sample C was an imported material. The media used were petrol, kerosene and distilled water. Other items used in carrying out the experiments were plastic containers, paper tape, mentholated spirit and plastic bowls.

\subsection{Equipment}

The following equipment were used in carrying out this work:

1. Spectrometer (Model SP-9268A). This was used for chemical analysis of the alloy samples.

2. Sensitive weighing balance (Model FX700CT)

3. Metallurgical Microscope (Model XZJ-L2030B)

4. Potentiostate (Model 1287A)

\subsection{Test Methods}

\subsubsection{Weight loss method}

The three alloy samples were cut into 15 coupons $(4 \mathrm{~cm} \mathrm{x} 4 \mathrm{~cm})$ totaling 45 pieces and were weighed (Figures 1 and 2). The plastic containers were first washed with detergent, rinsed in distilled water and allowed to dry for hours. They were then filled with petrol, kerosene and distilled water. The samples were completely immersed in petrol, kerosene and distilled water. Proper cleaning of each sample was ensured after removal using water and mentholated spirit. The samples were weighed (Figure 3) at 168, 336, 504, 672 and 840 hours (a span of 5 weeks) to determine the weight loss. The data collected from the experiment were analysed.

The corrosion rate was determined using Equation (1) developed by Callister and Rethwisch (2009):

$C_{R}=\frac{K W}{\rho A T}$

Where,

$W \quad$ Weight loss in $\mathrm{mg}$

$\rho \quad$ Density of the aluminum alloy in $\mathrm{g} / \mathrm{cm}^{3}$

$T \quad$ Immersion time in hrs

$K \quad$ Rate constant $(K=87.6$ for $\mathrm{mm} / \mathrm{yr})$ 


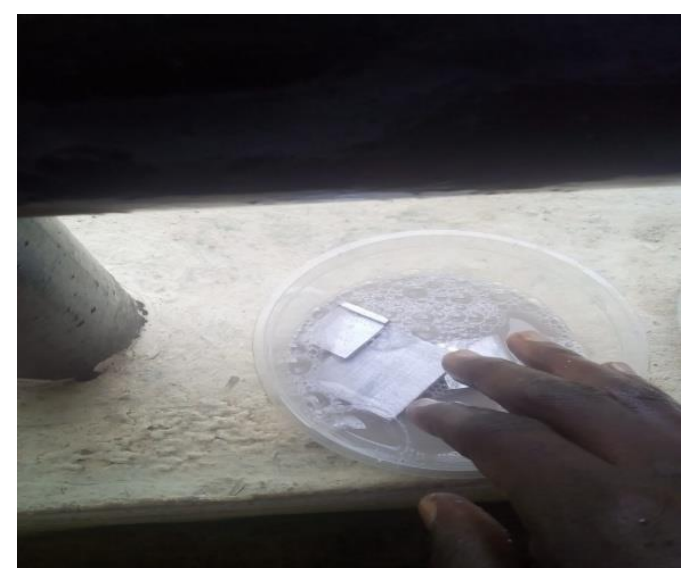

Figure 1: Preparation of samples for the weight loss experiment

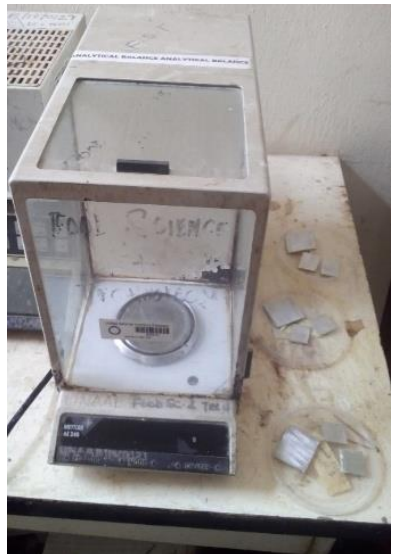

Figure 2: Weighing of the samples

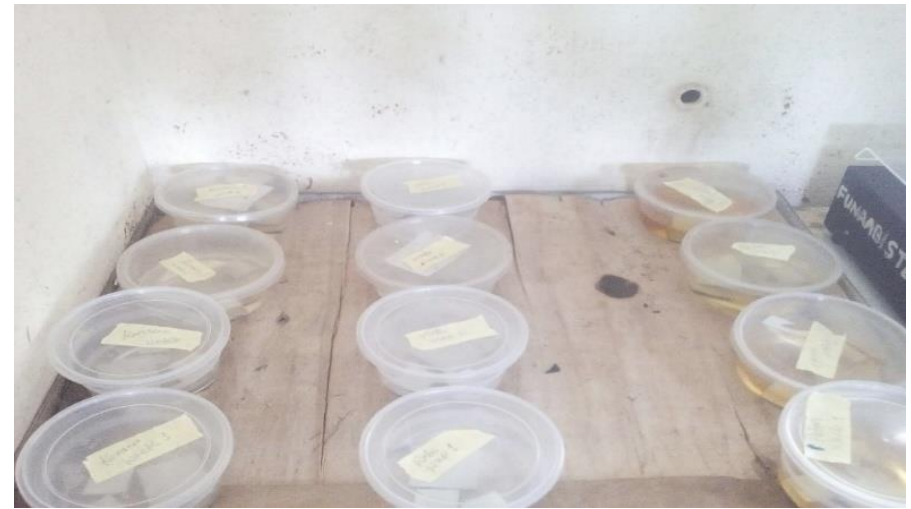

Figure 3: Weight loss experimental setup

\subsubsection{Potentiostatics experimental setup and process}

Corrosion analysis involves the particular surface of interest, and so other surfaces which were not required for the corrosion analysis were isolated. These were done using synthetic epoxy. Connecting wires were placed at one side of the sample and covered with a tape. Epoxy was prepared and placed all over the surface which was not needed for the corrosion analysis. The epoxy was then allowed to cure. This required a day or two to solidify. Continuity of the connection was checked to ensure proper connection between the wires and samples.

\section{Preparation of electrochemical cell:}

The basic electro-chemical cell involves a working electrode, reference electrode, counter electrode and solution media. Since the Working electrode (WE) is the electrode in an electrochemical system on which the reaction of interest is occurring.

The working electrodes were:

- Aluminum from the different sources: Samples (A), (B), (C)

- The reference electrode used was silver - silver chloride

- The counter electrode used was graphite electrode

The entire electrode was then dipped into the different media for each experiment to form the electrochemical cell.

\section{Determination of the open circuit potential:}

The equilibrium potential assumed by the metal in the absence of electrical connections to the metal is called the Open Circuit Potential, $E_{o c}$. The terms $E_{o c}$ (Open Circuit Potential) and $E_{c o r r}$ (Corrosion Potential) are usually interchangeable, but $E_{o c}$ is preferred. This is done by the use of a multimeter to measure the $E_{o c}$ value for the given electrochemical cell at a measured $\mathrm{pH}$ value. It is very important to allow sufficient time for the $E_{o c}$ to stabilize before beginning the electrochemical experiment. A stable $E_{o c}$ is taken to indicate that the system being studied has reached "steady state", i.e., the various 
corrosion reactions have assumed a constant rate. Some corrosion reactions reach steady state in a few minutes, while others may need several hours.

A graph plot of Potential versus logarithm of current was drawn using Origin 6.1. Polynomial line of best fit was drawn which obeys the Butler-Volmer equation for the cathodic corrosion occurring. The $E_{o c}$ potential was also plotted on the graph. Using Tafel analysis, an extrapolation of the linear portion of the cathodic curve to the corrosion potential to indicate the corrosion current $\left(I_{\text {corr }}\right)$ at which corrosion is occurring. The value of either the anodic or cathodic current at $I_{o c}$ is called the Corrosion Current.

\section{Monitoring of the electrochemical cell using the potentiostat:}

The different electrodes were connected to the potentiostat. This potentiostat was connected to a computer-controlled system. The corrosion monitoring was done in real time in which the values were determined from the computer Graphics User Interface (GUI), where a plot of voltage versus time and current versus time were displayed. The different reading for the current and voltage were then exported to excel for further analysis.

\section{Potential scan rate:}

This determines how slow or fast a potential window can be scanned. This is most important for experiments that require high scan rate. The experiment was run at a scan rate of $20 \mathrm{mV} / \mathrm{s}$. This was done to ensure that the potentiostat would detect a quantitative amount of corrosion i.e. the potentiostat does not run too fast and also does not run too slow.

\section{Corrosion rate analysis for potentiostatics:}

The corrosion rate for potentiostatics method was determined using Equation (2) according to ASTM G (1999):

$C_{R}(m p y)=\frac{K_{i} \times i_{c o r r} \times E W}{d A}$

Where,

$K_{i} \quad 3.272 \mathrm{~m} /($ amp-cm-year)

EW Equivalent weight

$d \quad$ Density in $\mathrm{kg} / \mathrm{m}^{3}$

A Cross sectional area of sample exposed to the medium in $\mathrm{mm}^{2}$

$I_{\text {corr }} \quad$ Corrosion current determined for data analysis in amps

\subsubsection{Microstructural examination}

The metallographic observations of the surface morphology of the samples after corrosion investigations let to estimate the kind and the stage of corrosive damages. Conducted investigations showed, that analyzed aluminum alloys after investigations in the media have diverse character of the damages of the surface.

Photomicrographs of samples after five weeks of immersion were taken using Metallurgical Microscope. The photomicrographs were done without etching to reveal the surface property at a magnification of $\mathrm{x} 400$ of the corroded material.

\subsection{Results and Discussion}

Table 1 shows the average value of the chemical compositions of samples A, B and C. It can be seen that the three samples have the same proportion of Silicon, Manganese and Boron. Sample A has the highest content of Titanium, Iron, Tin and Lead and least content of Zinc, while sample B has the highest content of Copper, and sample $\mathrm{C}$ has the highest content of Magnesium and Zinc. 
Table 1: Average values of the chemical wt \% composition of the samples

\begin{tabular}{lccccccccccccc}
\hline Element & $\mathrm{Mg}$ & $\mathrm{Si}$ & $\mathrm{Mn}$ & $\mathrm{Cu}$ & $\mathrm{Zn}$ & $\mathrm{Ti}$ & $\mathrm{Fe}$ & $\mathrm{Na}$ & $\mathrm{B}$ & $\mathrm{Sn}$ & $\mathrm{Pb}$ & $\mathrm{Al}$ \\
\hline Sample A & 0.3578 & 0.6165 & 0.0598 & 0.0949 & 0.2044 & 0.0305 & 0.6644 & 0.0036 & 0.0003 & 0.0036 & 0.007 & $<97.89$ \\
Sample B & 0.3875 & 0.5674 & 0.0659 & $>0.1012$ & 0.6760 & 0.0139 & $<0.4318$ & 0.0110 & 0.0003 & 0.0027 & 0.0041 & $<97.67$ \\
Sample C & 0.4092 & 0.5969 & 0.0636 & 0.0984 & 0.6864 & 0.0139 & $<0.4078$ & 0.0056 & 0.0003 & 0.001 & 0.0045 & $<97.67$ \\
\hline
\end{tabular}

The measured corrosion rate of Samples A, B and C immersed in petrol for a period of five (5) weeks using weight loss method is illustrated in Figure 4. The cumulative CR was determined at the end of each week. It showed that the CR measured at the end of first, second, third, fourth and fifth weeks for Sample A are 2.385, 1.789, 5.962, 1.789 and 3.577 respectively. For Sample B we have 8.479, 1.060, 6.36, 2.120 and 3.816 respectively; and for Sample C we have 6.360, 5.299, 4.946, 3.180 and 2.967.

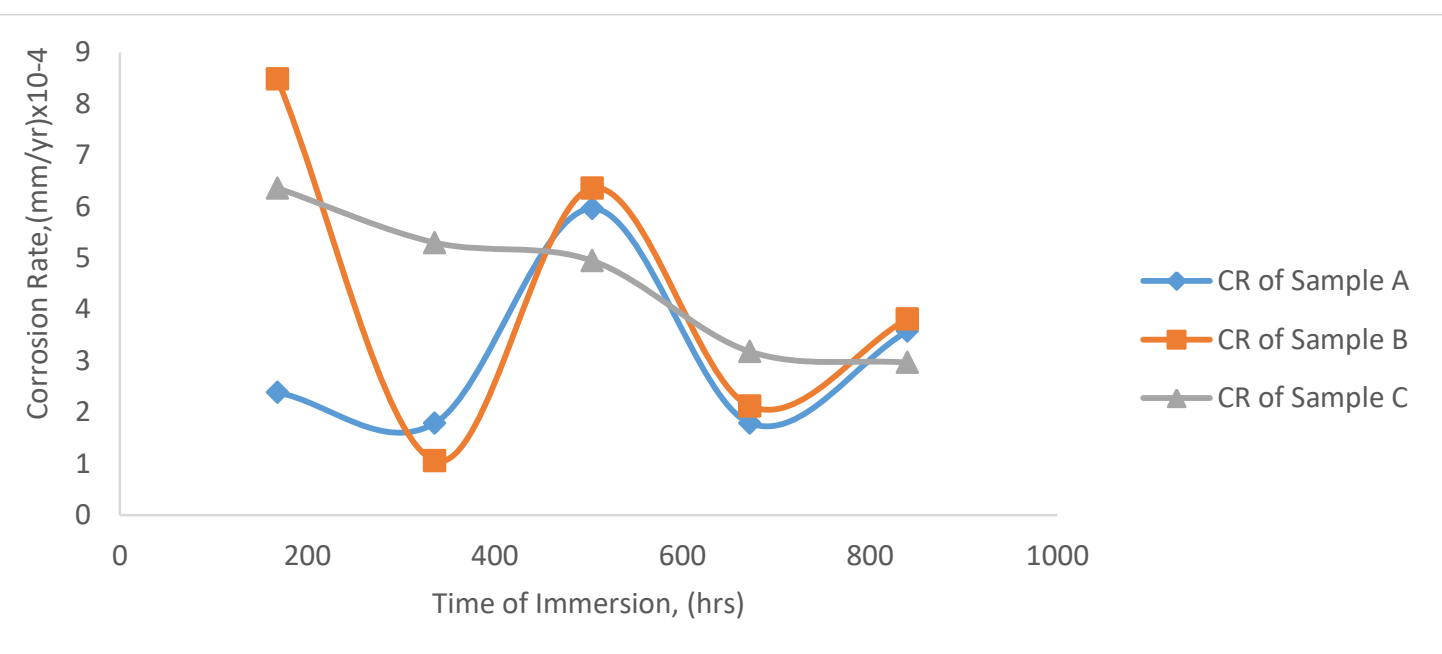

Figure 4: Corrosion rate in petrol

Figure 5 illustrate the measured corrosion rate of Sample A, B and C immersed in kerosene for a period of five (5) weeks using weight loss method. The cumulative CR measured at the end of first, second, third, fourth and fifth weeks for Sample A are 2.385, 5.366, 1.153, 6.558 and 9.062. Also for Sample B we have 6.360, 4.240, 0.156, 2.650 and 0110. Similarly, for Sample C we have 0.148, $5.299,0.116,5.299$ and 0.419 .

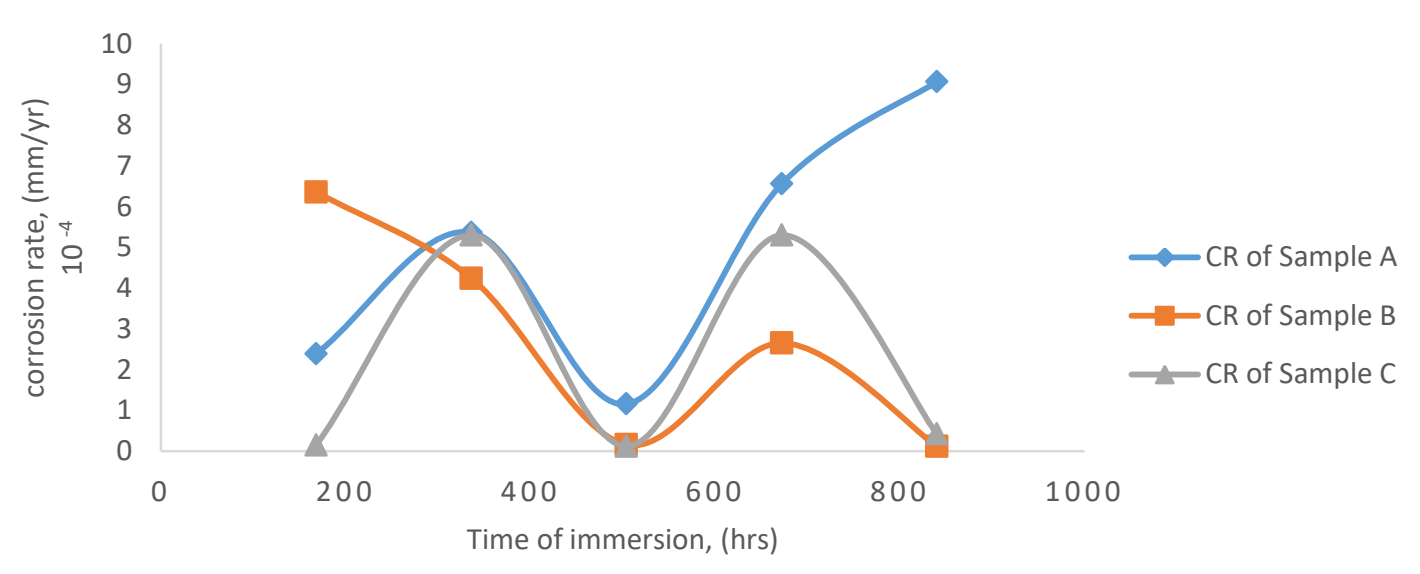

Figure 5: Corrosion rate in kerosene

The measured corrosion rate of Samples A, B and C immersed in distilled water for a period of five (5) weeks using weight loss method was illustrated in Figure 6. The cumulative CR was determined at the end of each week, for Sample A are 4.770, 6.558, 9.142, 5.068, 5.485 and 5.485 Also for Sample B we have 8.418, 0.180, 0.141, 0.3371 and 1.696. Similarly, for Sample C we have 0.636, 0.201, $0.120,4.240$ and 2.968 in respect order. 


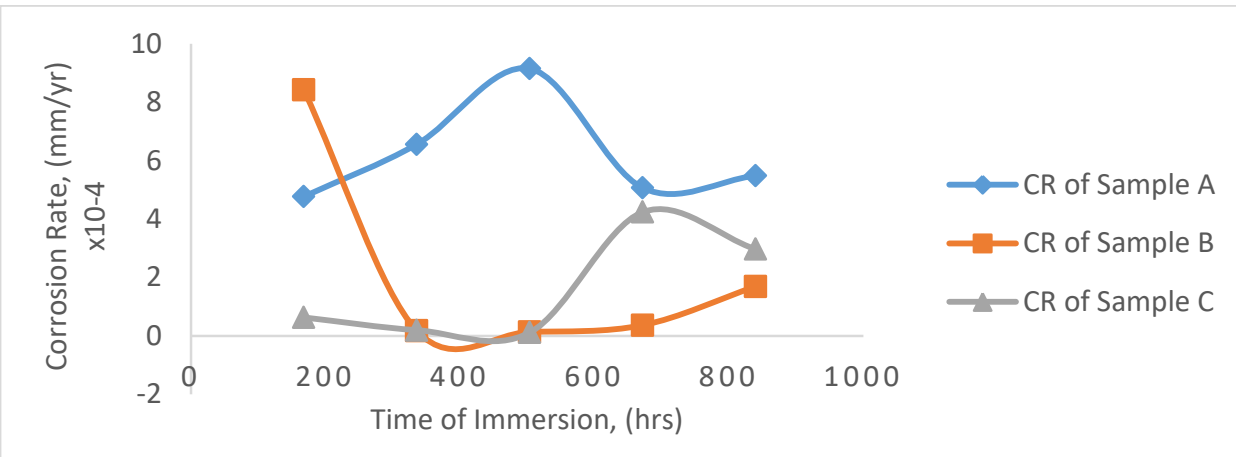

Figure 6: Corrosion rate in distilled water

Table 2 shows that sample A had the highest mean corrosion rate of $\left(3.100 \times 10^{-4} \mathrm{~mm} / \mathrm{yr}\right)$ followed by sample B $\left(4.367 \times 10^{-4} \mathrm{~mm} / \mathrm{yr}\right)$ and sample C $\left(4.550 \times 10^{-4} \mathrm{~mm} / \mathrm{yr}\right)$, respectively in Petrol. It can be seen that sample $\mathrm{C}$ had the highest mean corrosion rate $\left(2.257 \times 10^{-4} \mathrm{~mm} / \mathrm{yr}\right)$ in kerosene, followed by samples B $\left(2.703 \times 10^{-4} \mathrm{~mm} / \mathrm{yr}\right)$ and A $\left(4.905 \times 10^{-4} \mathrm{~mm} / \mathrm{yr}\right)$ respectively. Moreover, sample $\mathrm{C}$ had the highest mean corrosion rate $\left(1.633 \times 10^{-4} \mathrm{~mm} / \mathrm{yr}\right)$ in distilled water, followed by samples B $(2.147 \mathrm{x}$ $\left.10^{-4} \mathrm{~mm} / \mathrm{yr}\right)$ and $\mathrm{A}\left(6.205 \times 10^{-4} \mathrm{~mm} / \mathrm{yr}\right)$ respectively.

Table 2: Mean values of corrosion rate of each sample in the media using weight loss method

\begin{tabular}{lccc}
\hline \multirow{2}{*}{ Media } & \multicolumn{3}{c}{ Mean corrosion rate $(\mathrm{mm} / \mathrm{yr}) \times 10^{-4}$} \\
\cline { 2 - 4 } & Sample A & Sample B & Sample C \\
\hline Petrol & 3.100 & 4.367 & 4.550 \\
Kerosene & 4.905 & 2.703 & 2.257 \\
Water & 6.205 & 2.147 & 1.633 \\
\hline
\end{tabular}

Tables 3 to 5 show the corrosion potential $\left(E_{o c}\right)$, corrosion current $\left(I_{c o r r}\right)$ and the corrosion rate for the three samples immersed in petrol, kerosene and distilled water, as determined using the potentiostatic method.

Table 3: Corrossion Potential $\left(E_{o c}\right)$ of the samples in the different media using Potentiostatic method

\begin{tabular}{lccc}
\hline Samples & $\mathrm{A}$ & $\mathrm{B}$ & $\mathrm{C}$ \\
\hline Kerosene & $13.4 \mathrm{mV}$ & $-3.3 \mathrm{mV}$ & $0.1 \mathrm{mV}$ \\
Petrol & $-2.5 \mathrm{mV}$ & $-2.6 \mathrm{mV}$ & $-18.3 \mathrm{mV}$ \\
Distilled water & $-0.1 \mathrm{~V}$ & $0.4 \mathrm{~V}$ & $0.56 \mathrm{~V}$ \\
\hline
\end{tabular}

Table 4: Corrosion current $\left(\mathrm{I}_{\text {corr }}\right)$ for the different samples in the different media using Potentiostatic method

\begin{tabular}{lccc}
\hline Samples & A & B & C \\
\hline Kerosene & $4.53 \mathrm{~mA}$ & $13.6 \mathrm{~mA}$ & $3.78 \mathrm{~mA}$ \\
Petrol & $4.72 \mathrm{~mA}$ & $12.4 \mathrm{~mA}$ & $2.98 \mathrm{~mA}$ \\
Distilled water & $6.85 \mathrm{~mA}$ & $9.6 \mathrm{~mA}$ & $6.63 \mathrm{~mA}$ \\
\hline
\end{tabular}

Table 5: Corrosion Rate (mpy) for the samples in media using Potentiostatic method

\begin{tabular}{lccc}
\hline Samples & A & B & C \\
\hline Kerosene & $0.643 E-3$ & $0.197 E-3$ & $0.232 \mathrm{E}-3$ \\
Petrol & $0.586 \mathrm{E}-3$ & $0.206 \mathrm{E}-3$ & $0.183 \mathrm{E}-3$ \\
Distilled water & $0.454 \mathrm{E}-3$ & $0.298 \mathrm{E}-3$ & $0.407 \mathrm{E}-3$ \\
\hline
\end{tabular}

The photomicrographs of the samples immersed in the media for five weeks are displayed in plates 19. Plates 1,2 and 3 show photomicrograph of samples A, B and C in petrol after 5 weeks of immersion at a magnification of $\mathrm{x} 400$. 


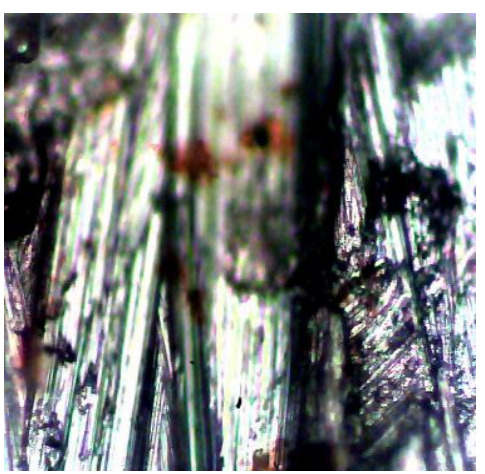

Plate 1

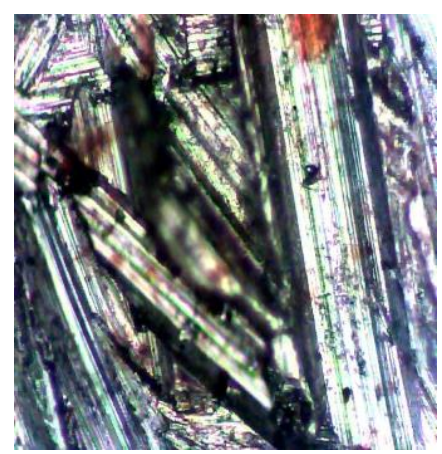

Plate 2

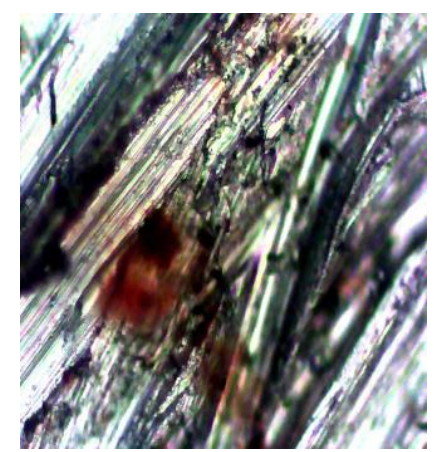

Plate 3

Plates 4, 5 and 6 show photomicrograph of samples A, B and C in kerosene after 5 weeks of immersion at a magnification of $\mathrm{x} 400$.

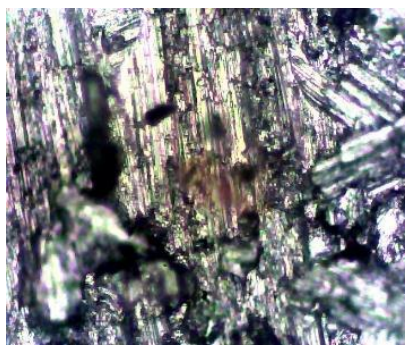

Plate 4

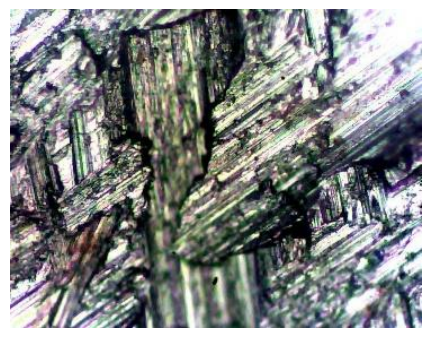

Plate 5

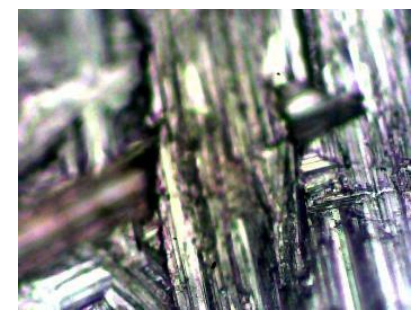

Plate 6

Plates 7, 8 and 9 show photomicrograph of samples A, B and C in distilled water after 5 weeks of immersion at a magnification of $\mathrm{x} 400$.

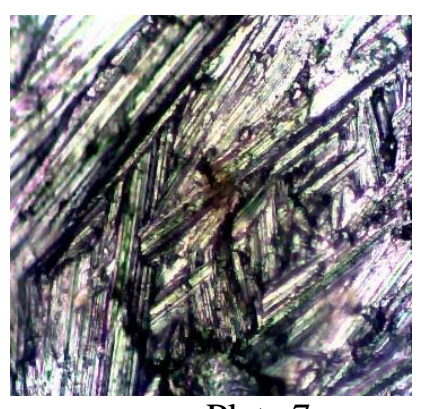

Plate 7

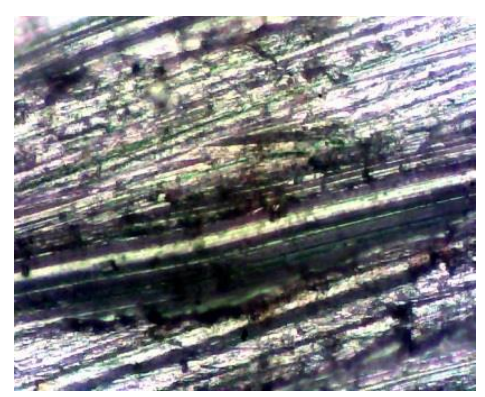

Plate 8

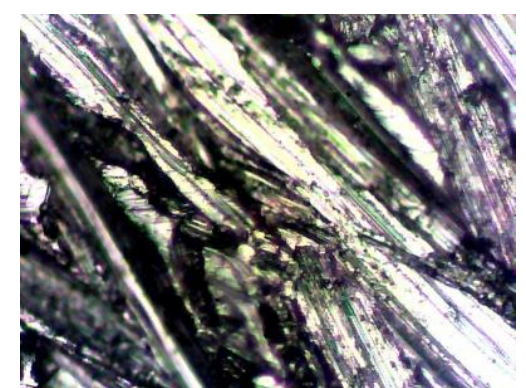

Plate 9

The increased corrosion resistance of pure aluminum is mainly attributed towards the formation of stable oxide layer on its surface. The addition of Silicon and Magnesium as alloying elements in case of 6063 aluminum could lead to the discontinuities on the oxide film, thereby increasing the number of sites where corrosion can be initiated. This increases the corrosion rate of 6063 aluminum (Padmalatha, 2013; Pardo et al., 2003; Trowsdale et al., 1996) as obtained in this study.

However, Larsen et al. (2010) found that copper is significant in increasing rate of corrosion in 6063 aluminum. The percentage of copper in Sample B was the highest but Sample A had the highest percentage by weight of iron and tin in the three samples which explained its higher corrosion rate compared to other samples. Pure aluminum consists of $0.120 \%$ Silicon, $0.270 \%$ Iron with $99.61 \%$ of aluminum. The 6063 aluminum consists of the items as stated in Table 1. It is noted that none of the samples had aluminum of up to $98 \%$. This explained the increased rate of corrosion that was observed. 


\subsection{Conclusion}

Two different corrosion test methods were evaluated in this report to evaluate their effectiveness in assessing corrosion performance of the samples. In addition, comparisons between the results were made. Based on the results, it was observed that sample A had the highest corrosion rate in the kerosene and distilled water while sample $\mathrm{C}$ had the highest in petrol. To store kerosene and distil water, sample A should therefore be used while sample $\mathrm{C}$ should be used to store petrol.

\section{References}

Al-Karafi, F. M. \& Badawy, W. A. (1996). Stability of anodically passivated Al, Al-Cu, AI-6061 and AI-7075 in nitric acid and nitric acid solutions containing chloride. Indian Journal of Chemical Technology, 3(4), 212-218.

Belkhaouda, M., Bazzi, L., Salghi,R., Jbara, O., Benlhachmi, A., Hammouti, B. \& Douglad, J. (2010). Effect of the heat treatment on the behavior of the corrosion and passivation of 3003 aluminium alloy in synthetic solution. Journal of Material and Environmental Science, 1(1), 25-33.

Callister, D. W. Jr. \& Rethwisch, G. D. (2009). Material Science and Engineering, 8th Edition, John Wiley and Sons Inc. Chapter 17, 682-683.

Davis J. R. (2001). Alloying: Understanding the Basics. ASTM International, 351-416.

Kciuk, M., Kurc, A., \& Szewczenko, J. (2010). Structure and Corrosion Resistance of Aluminium Almg2.5; AlMg5mn and AlZn5Mg1 Alloys. Journal of Achievements in Materials and Manufacturing Engineering, 41(1-2), 74-81.

El-Shafei, A. A., Abd El-Maksoud, S. A., \& Fouda, A. S. (2004). The role of indole and its derivatives in the pitting corrosion of $\mathrm{Al}$ in neutral chloride solution. Corrosion Science, 46(3), 579 590 .

Larsen, H. M., Walmsley, C. J., Lunder, O. \& Nisancioglu K. (2010). Effect of Excess Silicon and Small Copper Content on Intergranular Corrosion Of 6000-Series Aluminum Alloys. Journal of the Electrochemical Society, 157 (2), C61-C68.

Melchers, E. R. (2015). Time Dependent Development of Aluminum Pitting Corrosion. Advances in Materials Science and Engineering, Article ID 215712, 10 pages. http://dx.doi.org/10.1155/2015/215712.

Nuhu, A. A. (2012). Inhibition Characteristics of Watermelon Oil on Aluminium in Acids and Saline Water. AU Journal of Technology, 15(4), 265-272.

Padmalatha, P. D. (2013). Studies of Corrosion of Aluminum and 6063 Aluminum Alloy in Phosphoric Acid Medium. International Journal of ChemTech Research, 5(6), 2690-2705.

Pardo, A., Merino, M. C., Merino, S., Lopez, M. D., Viejo, F. \& Carboneras, M. (2003). Influence of reinforcement grade and matrix composition on corrosion resistance of cast aluminum matrix composites (A3xx.x/SiCp) in a humid environment. Material Corrosions, 54, 311-317.

Seri, O. \& Kido,Y. (2009). Corrosion Phenomenon and Its Analysis of 6063 Aluminum Alloy in Ethyl Alcohol. Materials Transactions, 50(6), 1433 -1439.

Sheasby, P.G. \& Pinner, R. (2001). The Surface Treatment and Finishing of Aluminum and Its Alloys, 6th Edition, ASTM International. Available at: www.asminternational.org

Syed, S. (2006). Atmospheric Corrosion of Materials. Emirates Journal for Engineering Research, 11 (1), 1-24. 
Trowsdale, A.J., Noble, B., Harris, S. J., Gibbins, I. S. R., Thompson, G. E., \& Wood, G. C. (1996). The influence of silicon carbide reinforcement on the pitting behaviour of aluminum. Corrosion Science, 2, 177-191. 